\title{
Organo-phosphorus flame retardants when applied to acrylonitrile-butadiene-styrene copolymer
}

- Woojung Kim

Sungkyunkwan University, Korea

- $\quad$ Dong Quy Hoang Thi

University of Science, VNU-HCM

Email: htdquy@hcmus.edu.vn

(Received on $9^{\text {th }}$ March 2017, accepted on $24^{\text {th }}$ May 2017)

\begin{abstract}
In order to find an effective halogen-free flame retardant for acrylonitrile-butadienestyrene copolymer (ABS), organo-phosphorus compounds were studied and their flame retarding performances were determined by UL 94 vertical test. It is found that the flame retardancy strongly

depends on phosphorus $(P)$ content of organophosphorus compounds. Only the mixture of $A B S$ with 2-(6-oxido-6H-

dibenz $<c, e><1,2>$ oxaphosphorin-6-yl) methyl diethyl phosphinate (ODOPM-DE), which has the highest $P$ content, i.e., $17.68 \%$ gives $V-0$ rating for the 70/30 composition.
\end{abstract}

Keywords: flame retardancy, organo-phosphorus flame retardant, DOPO, phosphorus content

\section{INTRODUCTION}

Polymers are a large and growing fraction of the fire load in homes, commercial environment, and transportation. However, the flammability of organic polymers limits their applications and fire hazard may be greatly increased when these materials are used unsuitably [1-3]. Halogenbased flame retardants, especially aromatic bromine compounds, are the most widely used in polymeric materials. However, so that the generation of toxic, corrosive, and halogenated gases in processing and the release of polybrominated dibenzo-p-dioxins (PBDDs), polybrominated dibenzofurans (PBDFs) in combustion might be avoided, there is a trend toward using non-halogen flame retardants in polymeric materials [4-5]. For example, EU forbids the use of polybrominated biphenyls (PBBs), polybrominated diphenylethers (PBDEs) in electric and electronic materials. Among the flame retardants containing nitrogen, silicone, phosphorus elements, organo-phosphorus compounds, generating less toxic gases and smoke, are the materials of choice [6-7]. Triphenyl

\section{Trang 192}

phosphate (TPP, Fig. 1(A): structure of TPP) and its analogues are widely known to be the most effective flame retardants for many polymers. But, because the evaporation temperatures of TPP and its analogues are lower than the processing temperature of various polymers, they are not suitable to avoid a considerable amount of TPP to evaporate during processing. On the other hand, aromatic bisphosphates are more thermally stable than monophosphates, tetra-2,6-dimethyl phenyl resorcinol diphosphate (DMP-RDP, Fig. 1(B): structure of DMP-RDP), is one of the phosphorus flame retardant exhibiting higher evaporation temperature compared to TPP. But, when DMPRDP was employed to examine the flame retardancy, it didn't exhibit the UL94 V-0 rating in styrenic polymers by itself [8].

Flame retardant can be chemically bonded to the macromolecular chain (reactive type) or dispersed mechanically in the polymer matrix (additive type). So far, there have been several approaches to the use of 9,10-dihydro-9-oxa-10- 
phosphaphenanthrene-10-oxide (DOPO, Fig. 1(C): structure of DOPO) by being incorporated into the backbone of the epoxy resin or the amine hardeners [9-10]. However, the phosphorus content of DOPO is low so that it also didn't exhibit the UL94 V-0 rating in styrenic polymers by itself. In this work, cyclic phosphorus compound of DOPO was used to synthesized 2-(6oxide- $6 H$-dibenz $<$ c,e $><1,2>$ oxaphos-phorin-6-

yl) methanol (ODOPM) via a simple addition reaction. The obtained compound with reactive methanol group was then used to continue the reaction to obtain flame retardant with high phosphorus content.

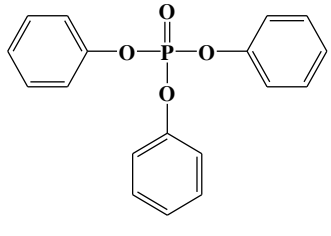

(A) TPP, P $\%=9.49$

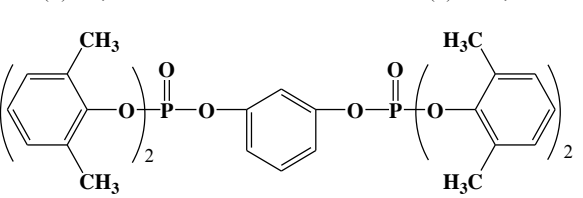

(B) DMP-RDP, P \% $=13.94$

Fig. 1. Chemical structures and $P$ contents of the studied organo-phosphorus compound: (A) TPP, (B) DMP-RDP, and (C) DOPO

\section{MATERIALS AND METHODS}

\section{Raw Materials}

9,10-dihydro-9-oxa-10-phosphaphenanthrene10-oxide (DOPO) was obtained from Tokyo Kasei Kogyo Co. of Japan. 2-(6-oxido-6Hdibenz $<$ c,e $><1,2>$ oxaphosphorin-6-yl) methanol (ODOPM) was prepared by reacting DOPO with paraformadehyde [8]. Paraformaldehyde was received from Aldrich and used without further purification. Xylene, dioxane, ethyl ether, triethylamine (TEA), thionyl chloride, and pyridine of reagent grades were received from Samchun Chemical Company of Korea and used as received. Diethylphosphinic chloride was prepared in our laboratory by adopting the synthesis method found in the literature [11].

Synthesis of diethylphosphinic chloride

Diethylphosphinic acid (122.1 g, $1 \mathrm{~mol})$ obtained from Cheil Industries was placed in a roundbottom flask equipped witha temperature controller and a reflux condenser. Thionyl chloride (237.94 g, 2 mol) was added dropwise. The mixture was heated to $75{ }^{\circ} \mathrm{C}$ and refluxed at that temperature for $3 \mathrm{~h}$. The reaction product was concentrated on a rotary evaporator, and diethylphosphinic chloride was obtained with a yield of $94 \%\left({ }^{31} \mathrm{P}-\mathrm{NMR}\left(\mathrm{CDCl}_{3}\right)\right.$ : a singlet peak at $\delta=76.6 \mathrm{ppm})$.

\section{Characterization}

FT-IR spectra were recorded with an infrared spectrophotometer (Nicolet 380 ). ${ }^{1} \mathrm{H}-$ and ${ }^{31} \mathrm{P}$ NMR spectra were taken on a Varian Unity Inova $500 \mathrm{NB}$ spectrometer. The chemical shift of ${ }^{31} \mathrm{P}-$ NMR spectrum is relative to the external standard of $85 \% \mathrm{H}_{3} \mathrm{PO}_{4}$.

Differential scanning calorimeter (DSC) was carried out on a TA 2910 DSC instrument at a heating rate of $10{ }^{\circ} \mathrm{C} / \mathrm{min}$ under a flow of $\mathrm{N}_{2}$ gas.

The UL $94 \mathrm{~V}$ test was performed according to the testing procedure of FMVSS 302/ZSO 3975 with test specimen bar of $127 \mathrm{~mm}$ in length, 12.7 $\mathrm{mm}$ in width, and about $12.7 \mathrm{~mm}$ in thickness. During the test, the specimen was subjected to two 10 -s ignitions with butane gas flame. Cotton ignition would be considered if material dripping occurred during the test. After the first ignition, the flame was removed and the time for the sample to self-extinguish $\left(\mathrm{t}_{1}\right)$ was recorded. A second ignition was applied on the same sample; the selfextinguishing time $\left(t_{2}\right)$ and dripping characteristic were recorded. If the sum $t_{1}$ and $t_{2}$ was less than $10 \mathrm{~s}$ with no dripping, the sample would be classified a V-0 ranking.

\section{RESULTS AND DISCUSSION}


SCIENCE \& TECHNOLOGY DEVELOPMENT JOURNAL:

NATURAL SCIENCE, VOL 1, ISSUE 6, 2017

\section{Synthesis of 2-(6-oxido-6H- \\ dibenz $<$ c,e $><1,2>$ oxaphosphorin-6-yl) methyl diethyl phosphinate (ODOPM-DE)}

ODOPM (123.1 g, $0.5 \mathrm{~mol})$, TEA (50.6 g, 0.5 $\mathrm{mol})$, and dioxane $(200 \mathrm{ml})$ were introduced into a 1 liter round bottom flask equipped with a nitrogen inlet, an overhead stirrer, a temperature controller, and a reflux condenser. The mixture was kept at 0 ${ }^{\circ} \mathrm{C}$ and diethylphosphinic chloride (70.3 g, 0.5 mol) was added dropwise over $1 \mathrm{~h}$. After the completion of diethylphosphinic chloride addition, the reaction mixture was heated to $90^{\circ} \mathrm{C}$ and refluxed at that temperature for $5 \mathrm{~h}$. The reaction mixturewas cooled down to room temperature. Triethylaminehydrochloride salt was filtered off and the filtrate was evaporated under reduced pressure to give the crude product.The yellowish solidof ODOPM-DE was obtained by washing the crude product with ethyl ether thoroughly. The yield of ODOPM-DE (m.p. 110$111^{\circ} \mathrm{C}$ (Fig. 2)) was $90 \%$. The IR spectrum (KBr) exhibited absorptions at $1200-1240$ and $1280 \mathrm{~cm}^{-}$ ${ }^{1}$ ( $\mathrm{P}=\mathrm{O}$ vibration), $1060 \mathrm{~cm}^{-1}$ (P-O-C (aliphatic) stretching), $933 \mathrm{~cm}^{-1}$ (P-O-Ph, stretching), 2880$2970 \mathrm{~cm}^{-1}$ (C-H sat.), $3070 \mathrm{~cm}^{-1}$ (C-H unsat.) (Fig. $3)$. The shift and splitting patterns of ${ }^{1} \mathrm{H}-\mathrm{NMR}$ $\left(\mathrm{CDCl}_{3}\right)$ spectrum was at $\delta=0.78-0.97(\mathrm{~m}, 6 \mathrm{H}$, $\left.\mathrm{P}-\mathrm{CH}_{2}-\mathrm{CH}_{3}\right), 1.39-1.58$ (m, 4H, P-CH2- $\left.\mathrm{CH}_{3}\right)$, 4.46-4.61 (m, 2H, P-O-CH2), 7.25-8.04 (m, 8H, Ar-H). (Fig. 4). ${ }^{31} \mathrm{P}-\mathrm{NMR}\left(\mathrm{CDCl}_{3}\right)$ : two singlet peaks were observed at $\delta=65.99\left(\mathbf{P}(\mathrm{O})-\mathrm{CH}_{2}-\right.$ $\mathrm{CH}_{3}$ ) and 30.64 (-CH $2-\mathrm{P}(\mathrm{O})-\mathrm{O}-$, cyclic). (Fig. 4).

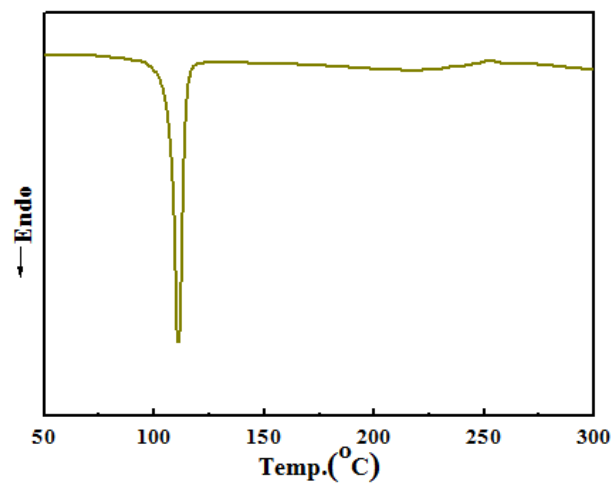

Fig. 2. DSC thermogram of ODOPM-DE

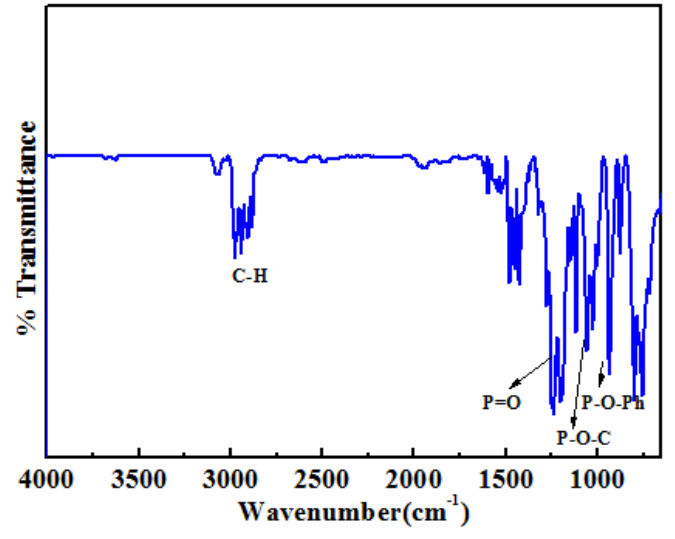

Fig.3. IR spectrum of ODOPM-DE
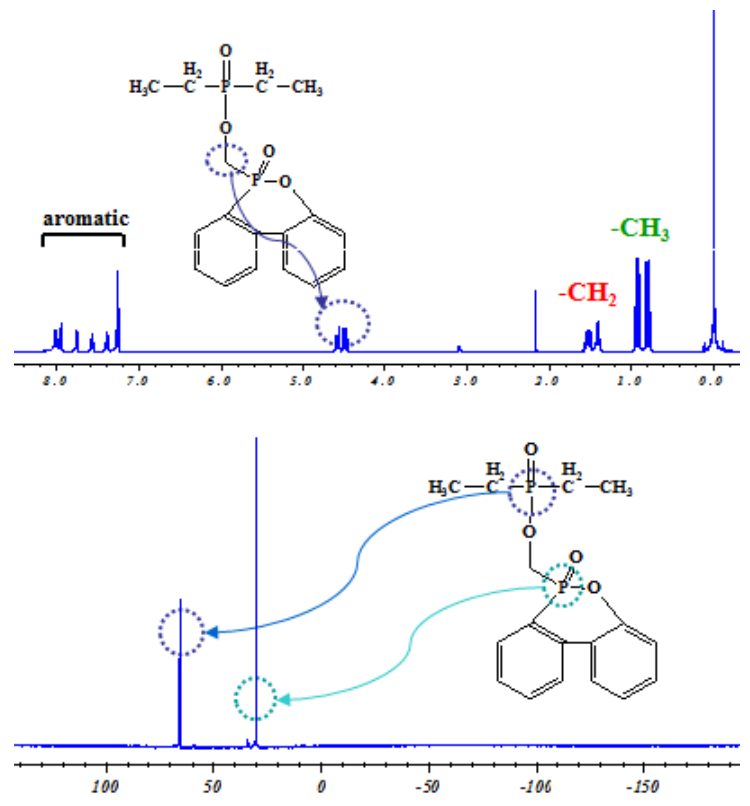

Fig.4. ${ }^{1} \mathrm{H}$ - and ${ }^{31} \mathrm{P}-\mathrm{NMR}$ spectra of ODOPM-DE UL 94V test

The UL 94V test determines the upwardburning characteristics of a solid and is considered as one of the industrial standards for determining the flame retardancy. To evaluate the efficiency of the flame retardant, $30 \mathrm{wt} \%$ of flame retardant

Trang 194 
was mixed with ABS using a HAAKE PlasticCorder mixer and undergone UL 94V test, whose results are given in Table 1. It was found that the mixture with ODOPM-DE gave V-0 rating while other mixtures burned completely. This result clearly indicated that the flame retardancy strongly depended on phosphorus content. In other words, more effective retardancy could be achieved by employing the organo-phosphorus with higher $\mathrm{P}$ content, which clearly supports that our approach to synthesize this material could be justified.

Table 1. UL 94V Test Results for Various 70/30 ABS/Organo-phosphorus Mixtures.

\begin{tabular}{lccc}
\hline \multicolumn{1}{c}{$\begin{array}{c}\text { Flame } \\
\text { retardant }\end{array}$} & $\begin{array}{c}\mathrm{P}(\%) \\
\text { inflame retardant }\end{array}$ & $\begin{array}{c}\mathrm{P}(\%) \\
\text { in } 70 / 30 \text { mixture }\end{array}$ & UL 94V rating \\
\hline TPP & 9.49 & 2.85 & Burning \\
DMP-RDP & 13.94 & 4.18 & Burning \\
DOPO & 14.33 & 4.30 & Burning \\
ODOPM-DE & 17.68 & 5.30 & V-0 \\
\hline
\end{tabular}

\section{CONCLUSION}

Organo-phosphorus compounds derived from DOPO were synthesized successfully and their structure was confirmed by FT-IR, ${ }^{1} \mathrm{H}-$, and ${ }^{31} \mathrm{P}-$ NMR spectra. Among three flame retardants used in this study, ODOPM-DE had the highest $\mathrm{P}$ content, i.e., $17.68 \%$, which was quite higher than that of DOPO. The flame retardancy of ODOPMDE, TPP, and DMP-RDP were examined by UL 94V test for the mixture with ABS. It was found that ODOPM-DE/ABS gave the V-0 rating for the $70 / 30$ mixture while the mixtures with other flame retardants burned completely in the same composition. This clearly indicated that flame retardancy strongly depended on the phosphorus content.

Acknowledgements: The authors appreciate the financial support the from Cheil Industries

\section{Hợp chất chống cháy phosphorus-hữu cơ ứng dụng trên nền vật liệuacrylonitrile- butadiene-styrene}

- Woojung Kim

Đại học Sungkyunkwan, Suwon, Hàn Quốc

- Hoàng Thị Đông Quỳ

Trường Đại học Khoa học Tự nhiên, ĐHQG-TPHCM

\section{TÓM TẮT}

Nhằm muc đích tìm ra hợp chất chống cháy phi halogen hiệu quả để ứng dụng trên nền vật liệu acrylonitrile-butadiene-styrene (ABS), các hợp chất chống cháy phosphorus-hũu co đã được nghiên cứu và khả năng chống cháy của chúng được đánh giá bằng phuoong pháp UL94V. Kết quả cho thấy tính chất chống cháy của các hợp chất chống cháy phosphorus-hũu co phu thuộc chủ yếu vào hàm luợng phosphorus. Và duy nhất hôn hợp 70/30
ABS/-(6-oxido-6H- 
dibenz $<c, e><1,2>$ oxaphosphorin-6-yl)

methyl diethyl phosphinate (ODOPM-DE) vói hàm luợng phosphorus của ODOPM-DE cao nhất (17,68\%) đã đạt chuẩn tối uu UL94V-0.

Tù khóa: phu gia chống cháy, phụ gia chống cháy Photpho, DOPO

TÀI LIỆU THAM KHẢO

[1]. C.J. Hilado, Flammability Handbook for Plastics, $5^{\text {th }}$ edition, Technomic Publishing Co., Lancaster, Pennsylvania (1998).

[2]. J. Troitzsch, Plastics Flammability Handbook, Hanser Publishers, Munich (2004).

[3]. Z. Horak, L. Rosik, in Styrene-based Plastics and Their Modification, eds. P. Svec, L. Rosik, Z. Horak, and F. Vecerka, Ellis Horwood, New York, 277-299 (1990).

[4]. P. Luijk, H.A.J. Govers, Thermal degradation characteristics of high impact polystyrene/decabromodiphenylether/antimo ny oxide studied by derivative thermogravimetry and temperature resolved pyrolysis - mass spectrometry: formation of polybrominated dibenzofurans, antimony (oxy)bromides and brominated styrene oligomers, J Anal Appl Pyrolysis, 20, 303-319 (1991).

[5]. R. Dumler, H. Thoma, Thermal formation of polybrominated dibenzodioxins (PBDD) and dibenzofurans (PBDF) from bromine containing flame retardants. Chemosphere, 19, 305-308 (1989).

[6]. Y. Nakamura, M. Yamaguchi, M. Okubo, T. Matsumoto. Effects of particle size on mechanical and impact properties of epoxy resin filled with spherical silica. J Appl Polym Sci., 45, 1281-1289 (1992).

[7]. K.S. Annakurtty, K. Kishore, Flame retardant polyphosphate esters: 1. Condensation polymers of bisphenols with aryl phosphorodichloridates: synthesis, characterization and thermal studies. Polymer, 29, 756-761 (1988).

[8]. V.S. Levchik, in conference on Recent Advances in Flame Retardancy of Polymeric Materials, Stamford, CT(2006).

[9]. C.S Wang, C.H. Lin,Synnthesis and properties of phosphorus containing polyarylates derived from 2-(6-oxido-6H-dibenz $\langle\mathrm{c}, \mathrm{e}\rangle\langle 1,2\rangle$ oxaphosphorin-6-yl)-1,4-dihydroxy phenylene.Polymer, 40, 4387-4398 (1999).

[10]. C.S. Wang, C.H. Lin. Synthesis and properties of phosphorus-containing epoxy resins by novel method, J. Polymer Sci. Polym Chem., 37, 3903-3909 (1999).

[11]. M.J.P. Harger, M.A. Stephen, Photochemical rearrangement of dialkylphosphinic azides in methanol and other protic solvents. J. Chem. Soc.; Perkin Trans, 1, 736-740 (1981).

\section{Trang 196}

